\title{
DISTANCE AND THE PATTERN OF INTRA-EUROPEAN TRADE
}

\author{
W. Beckerman
}

$\mathrm{T}$ HE basic question to which this paper is addressed is "What is the importance of distance in determining the pattern of Western European trade?" The importance of distance in the pattern of trade has, of course, always been recognized. The assumption of "no transport costs," which has always been necessary in expositions of theories of international trade, is a recognition of the fact that transport costs, that is, the costs of covering distance, exist and are significant; so that abstraction from them has to be made quite explicitly in order to analyze other elements such as factor endowments. ${ }^{1}$

First, it is necessary to abstract from the effect on the pattern of trade related simply to differences in the size of countries. Thus, Germany's imports from Greece are likely to be smaller than Germany's imports from France simply because the total exports of Greece are small relative to the total exports of France. Therefore, in order to explain the distribution of Germany's imports in terms of factors other than the relative size of the supplying countries, say, in terms of distance, relative prices, relative incomes, the data have to be corrected to eliminate the effect of differences in the size of the trade of the various countries. This may be done by adjusting every country to an "equal importer" or "equal exporter" basis. The framework used for this adjustment is as follows.

To facilitate statistical work, Western Europe is defined as the member countries of the O.E.E.C. The intra-European trade of these countries is arranged in the form of a trade matrix. The data used are the f.o.b. export figures as recorded by the exporting countries. Then in order to examine first the distribution

${ }^{1} A$ recent article by $W$. Isard and $M$. Peck contains some empirical evidence of the importance of transport costs in trade within the United States. This article also contains reference to related studies, such as that carried out in the x 920 's by the German National Bureau of Statistics. See Isard and Peck, "Location Theory and International and Interregional Trade," Quarterly Journal of Economics, LXVIII (February 1954), 97-I15. of each country's imports, all countries have been put on an "equal exporter" basis. To do this the elements in all the rows (exports) of all the countries have been multiplied by the coefficients (one for each row) required to bring the row totals up to (or down to) roo. Similarly, in order to examine the distribution of each country's exports, the data have to be adjusted to put each country on an "equal importer" basis by adjusting the columns relating to each country in such a way that they all total roo. The principal tables are in the form of trade matrices; there are two tables for each year examined, one in which the countries are adjusted to "equal exporter" basis, and one in which they are adjusted to "equal importer" basis. Three years have been covered in this study, namely, 1938, 1948, and 1953. The tables for 1938 and 1953 are shown in full in the Appendix. The tables for r 948 can be supplied by the writer upon request.

Concentration of trade. Before proceeding to analyze statistically the basic tables, certain features are immediately apparent. One of these is the abnormality of the distribution of the figures. Consider, for example, Appendix Table ra and examine the column for, say, Sweden. Fourteen other countries are listed as exporters to Sweden, so that if Sweden's imports were distributed evenly among them, each would account for $7.15 \%$ of her imports. (The discussion will proceed in terms of the equal importer or equal exporter basis unless otherwise specified.) If the distribution were not perfectly even but varied more or less according to some normal distribution, one would expect an accumulation of figures round the 7 per cent level, with few figures at either very high or very low percentages. In fact, as can be seen from the table, the reverse is the case. The figures seem to accumulate at the extremes - at high percentages ( $16.7 \%$ from Iceland, I $6.7 \%$ from Norway, I $2.0 \%$ from Germany) or at low percentages ( $1.07 \%$ from Greece, $0.07 \%$ from Ireland, $2.4 \%$ from Turkey). 
Sweden is not exceptional in this respect. The result is that, taking all the countries together, there is a relatively high number of very high or very low percentages, that is to say, high or low compared with the average of 7.I 5 per cent. $^{2}$ This can be seen in the frequency distribution in Table r. In short, after correcting for differences in the sizes of all countries' total imports and exports, imports and exports do not tend to be distributed in a statistically normal fashion among the other countries.

TAble I. - Frequency Distribution of Adjusted Percentage Distribution of Intra-European TRADE, I938

\begin{tabular}{ccccrr}
\hline \hline Class & Imports & Exports & \multicolumn{1}{c}{ Class } & Imports & Exports \\
\hline $0-1 \%$ & 44 & 45 & $7-8 \%$ & 9 & 7 \\
$1-2 \%$ & 15 & 23 & $8-9 \%$ & I0 & II \\
$2-3 \%$ & 20 & 25 & $9-10 \%$ & 2 & II \\
$3-4 \%$ & 23 & 15 & $10-11 \%$ & 6 & 3 \\
$4-5 \%$ & 25 & 19 & $11-12 \%$ & 5 & 0 \\
$5-6 \%$ & I2 & I3 & 12 $-13 \%$ & 8 & 5 \\
$6-7 \%$ & I0 & I4 & 13 $3 \%$ & 37 & 35 \\
\hline
\end{tabular}

The concentration of each country's trade may be represented by considering, for each country, what percentage of imports is supplied by the two or three most important suppliers of its imports. The results of such a calculation vary, of course, from country to country. The averages for all Member countries are shown in Table 2.

Table 2. - Concentration of Trade on Principal Suppliers and Princtpal Customers*

(In per cents)

\begin{tabular}{lcc}
\hline & 1938 & 1953 \\
\hline 2 Major Countries & & \\
Imports & 43.5 & 38.3 \\
Exports & 39.4 & 39.8 \\
3 Major Countries & & \\
$\quad$ Imports & 54.9 & 49.6 \\
Exports & 55.5 & 49.8
\end{tabular}

* Average percentage, for all O.E.E.C. members, of total intraEuropean imports/exports covered by major suppliers/customers.

\footnotetext{
2 The arithmetic mean is $7.15 \%$ for imports and $6.68 \%$ for exports in 1938. This is because in 1938 there are no Austrian trade figures, so that as the tables are based on export data for all countries Austria appears only as a destination of exports (as an importer) and not as an exporter.
}

These figures suggest three conclusions: (I) there is a striking degree of concentration of each country's trade on a small range of other countries, (2) the degree of concentration has declined somewhat between 1938 and r953, and (3) both these conclusions apply equally to imports and exports. Table 2 is only a rough guide, however, to the degree of concentration. Table 3 gives the Gini coefficients for imports and exports in 1938 and 1953, showing how far from a Lorenz curve distribution the trade percentages are. (Zero would measure equal distribution; unity would measure complete concentration.)

Table 3 confirms the conclusions, already reached on the basis of Table 2 , concerning the approximate equality of concentration of imports and exports and the decline in concentration between 1938 and $1953 .^{3}$

Table 3. - Gini Coefficient of Concentration for Trade of O.E.E.C. Member Countries

\begin{tabular}{lcc}
\hline & 1938 & 1953 \\
\hline Imports & .507 & .442 \\
Exports & .522 & .443 \\
\hline
\end{tabular}

Concentration and distance. We have seen the strong tendency of countries to concentrate their trade on a few other countries rather than spread it evenly. An even distribution would, in fact, be rather surprising, for various reasons. The object of this study, however, is simply to investigate the relationship between the manner in which the trade is distributed and the relative distances between countries.

The concept of "economic distance" relates to the cost of transversing distance rather than the actual mileage involved. Unfortunately, countries cannot be regarded as occupying only points in space between which the distances to be converted into economic distances are easily measured. Countries occupy large areas, and the concept of distance between areas depends

${ }^{8}$ Examination of the basic data (see Appendix) shows that the reduction in concentration is partly due to the changed relationship in the trade between Germany on the one hand and Greece and Turkey on the other. But the decline in trade concentration between 1938 and I 953 appears to be also partly due to a more general, though less marked, decline among the other countries of Europe. Only Norway and Portugal seem to be exceptions to the general trend. 
on such considerations as whether we conceive the distances between the areas to be the distances between the closest points, or between the geometrical centers, or between their "centers of gravity" as determined by some system of weighting.

For purposes of measuring the cost of transporting a commodity from one country to another, the appropriate concept would appear to be a mixture of these alternative measures. Products are likely to be shipped (or entrained) between points as proximate as possible. But the availability of harbor or railway facilities determines what is possible. On the other hand, somebody has to bear the cost of transporting the goods from the source of production to the export point, and from the import point to the final destination. This means that though in country I, port A may be nearer to country 2 than port $B$, the goods being exported to country 2 may be produced very near to port $B$ and a long way from port $A$. This qualification to distance brings us closer to the "center of gravity" concept - of course it is the economic center of gravity, rather than the physical center of gravity, that is relevant. ${ }^{4}$

Finally, even if there were some unique distance between countries in terms of some unit of distance such as miles, there is the problem of allowing for variation in the cost of alternative means of transport. The main problem here is the difference between sea and rail transport. While France is adjacent to Belgium the cost (per unit weight) of rail transport from the source of production in France to the final location of consumption in Belgium may be greater than the cost (per unit weight) of transport of some product manufactured in London and consumed in Oslo and which is therefore transported almost entirely by sea.

Before proceeding to a more detailed analysis

'This modification has important consequences. For example, measuring between "nearest points" France is clearly as close to Italy as it is to Belgium, since she is adjacent to both countries. Measured in terms of the geometrical center, she is again about as close to Italy as to Belgium (though not if we consider also the geometrical centers of Italy and Belgium as well - Italy's would be much further away). But measured in terms of economic center of gravity she is probably somewhat closer to Belgium than to Italy on account of the concentration of French industrial activity in the Paris region and the coal mining areas of northern France. of the relative distance between the countries represented in the basic tables, an assessment has been made, for each country, of which two or three countries are "nearest" to it in the sense described above. (The actual ordering of countries on which this selection has been based is shown in Table 5 below.) To do this an estimate has been made of the percentage of trade of each country going to the two or three nearest countries. The results for the average of O.E.E.C. Member countries are shown in Table $4 a$.

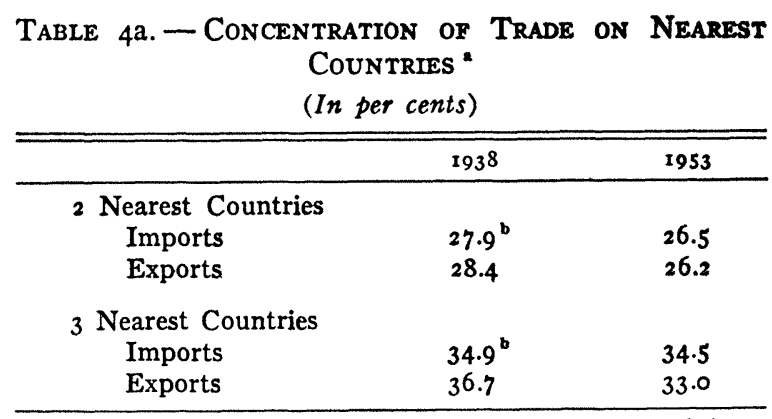

a Average percentage, for all O.E.E.C. members, of total intraEuropean imports/exports of each country coming from/going to the two or three nearest countries.

or three nearest count
See footnote 2 above.

As it stands, however, Table 4 a cannot accurately show the difference in the degree to which trade is concentrated on neighbors as between two and three countries, for even if there were no correlation at all between relative distance and concentration the percentage of trade covered by any three countries would be greater than that covered by any two countries. This, and other incomparabilities, means that the data have to be standardized by dividing all the figures by the percentages of trade that would be covered anyway by the number

Table 4b. Concentration of Trade on Nearest Countries, Standardized Data *

(In per cents)

\begin{tabular}{ccc}
\hline & 1938 & 1953 \\
\hline 2 Nearest Countries & & \\
Imports & 1.95 & 1.99 \\
Exports & 1.99 & 1.97 \\
3 Nearest Countries & & \\
Imports & 1.63 & 1.72 \\
Exports & 1.83 & 1.64 \\
\hline
\end{tabular}

* Average percentage, for all O.E.E.C. members, of total intraEuropean imports/exports of each country coming from/going to the lined in text. 
of countries specified if there were a perfectly even distribution. The result of this operation is given in Table $4 \mathrm{~b}$.

The above table suggests the following conclusions: (I) even allowing for statistical qualification there appears to be a strong tendency to concentrate trade on "near" countries; (2) this tendency is not so strong, however, if the three nearest countries are considered rather than the two nearest countries; (3) it is just as strong for exports as for imports; and (4) it does not appear to have declined between r938 and r953.

Thus far we have not discussed the problem of how to measure, in practice, the relative distances between countries in the sense outlined above. One possible measure would be to examine the mark-up between ( $I$ ) the f.o.b. average value of exports of certain specific goods as they appear in the export statistics of countries accompanied by specification of the destination of these exports and (2) the c.i.f. average value of those quantities of the same goods, which are specified as being imported from the corresponding countries, in the import statistics of the relevant importing countries. To take a hypothetical example, suppose that in French export statistics, exports of alcoholic beverages are shown by quantity and value and at the same time by destination. One could readily compute the average value (price) f.o.b. of French exports of alcoholic beverages to each main destination separately. Turning to the import statistics of each of these countries in which similar data are available, one could readily compute the average value c.i.f. of their imports of alcoholic beverages from France. The mark-up for each country will vary, and the differences in this mark-up should indicate roughly the relative costs (including insurance, etc.) of sending alcoholic beverages to each of the countries concerned. ${ }^{5}$

In actual practice, this procedure is subject to several limitations, owing to various defects of international trade statistics. For example, the time period concerned may not be identical for both countries, since products may be recorded in French export statistics long before

\footnotetext{
${ }^{5}$ The source actually used in this study is O.E.E.C. Statistical Bulletins, Foreign Trade, Series IV.
}

they are recorded in the importing statistics of the recipient countries. The exact classification of products is also not identical in all countries. There may also be substantial changes in the weight of some products (for example, tobacco) that rest in bond for a long time between being officially exported and officially imported. There may be discrepancies arising from transit trade - country A may show, in its export statistics, that a certain quantity of some product has been exported to country B, but it is possible that a part of this amount has not been officially imported into country $B$ at all, and that it was merely a transit transaction. If the average value of this part of the commodity in trade differs substantially from that of the rest then the procedure outlined above will give an incorrect result.

In view of such difficulties the above method of estimating distance has been used to obtain only a rough ordinal comparison of distances rather than a cardinal comparison. That is to say the limitations on the data enable us to say only that country $A$ is further from country $Z$ than is country $B$, but we cannot say by how much. Even the mere ordering of countries can only be carried out with a rough accuracy by this method. This is largely because, in many cases it has not been possible to find enough products giving sufficient pairs of statistics (on the import side and on the export side) for a reliable averaging of the mark-ups. A large number of observations are needed because otherwise there are inconsistencies in the results. For example, according to the data for one product Germany is nearer to Greece than is Denmark, but according to the data for another product the reverse result may be obtained.

For these and other reasons the sort of data referred to above can only be used to give a rough ordering of the relative distances between countries. In some cases obvious errors can be legitimately corrected by simple knowledge of geography. For example, the following results of percentage mark-ups is obtained for Sweden on the basis of her trade in paper and paperboard. ${ }^{6}$

$$
{ }^{6} \text { S.I.T.C. No. } 641 \text {. }
$$




\begin{tabular}{l} 
Country \\
\hline Denmark \\
Belgium \\
Norway \\
Netherlands \\
Germany \\
Ireland \\
U.K. \\
France \\
Italy \\
Portugal \\
Turkey \\
Greece
\end{tabular}

\begin{tabular}{c} 
Percentage Mark-up \\
\hline$-1 \%$ \\
$+1 \%$ \\
$+5 \%$ \\
$+6 \%$ \\
$+6 \%$ \\
$+8 \%$ \\
$+9 \%$ \\
$+10 \%$ \\
$+12 \%$ \\
$+14 \%$ \\
$+23 \%$ \\
$+28 \%$
\end{tabular}

It will be obvious from inspection that in the absence of fully reliable statistical indicators there is a considerable element of uncertainty about the ordering of countries which are close together. For example, in the column relating to Belgium, the exact ordering of the Netherlands, France, and Germany is liable to be erroneous. It is on account of the absence of sufficiently reliable statistical data that not all countries could be included in Table $5 .{ }^{7}$

Table 5. Ranking of Countries in Order of Estimated Economic Distance FROM SELECTED COUNTRIES *

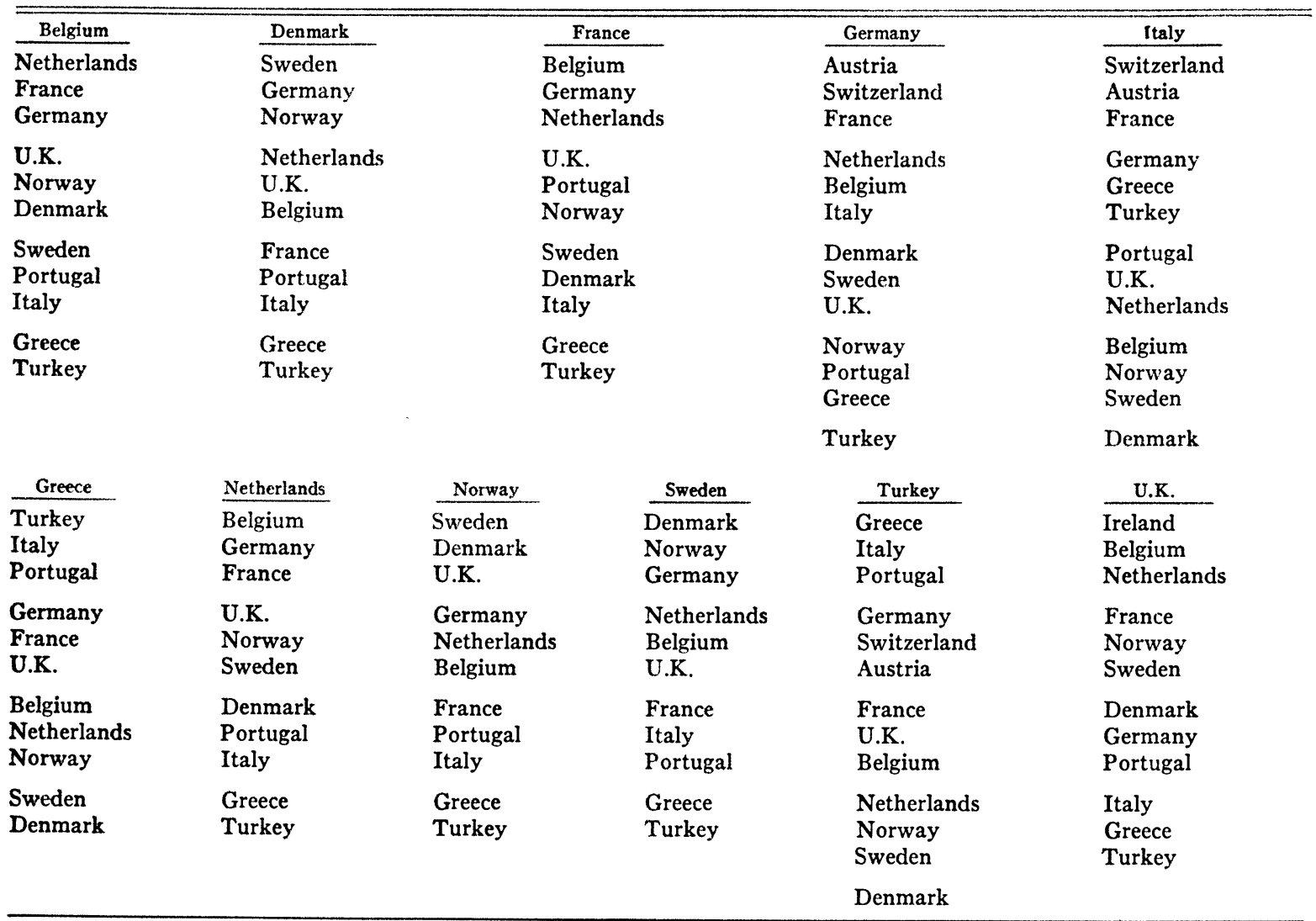

- Some countries have been given a longer list than others. This depends on how many countries it has been possible to order for each selected country on the basis of the technique described in the text. It will be observed, for example, that Switzerland only appears in the columns relating to Italy and Germany, and Austria in the columns of these two countries, plus Turkey.

If one is attempting only to order the countries, one can probably improve the above ranking by, say, transposing Greece and Turkey (Turkey should be "further away" from Sweden than is Greece), or Norway and Belgium, and so on. On the basis of evidence for other products and including any adjustments that seem to be reasonably certain, the countries were ordered as shown in Table 5 .
Such inaccuracies in the ordering are just as likely to reduce the correlation coefficients which have been calculated below as to increase them.

Being limited to ranked data, the obvious

\footnotetext{
${ }^{7}$ Switzerland does not publish any trade data of the type required here and only appears when fairly good judgments can be made (namely, in the columns for Germany and Italy).
} 
test of a relationship between distances and importance in trade is the Spearman rank correlation coefficient. Applied here, this coeffcient measures, roughly speaking, the strength of the relationship between the ranking of countries with respect to their relative distance from a given country and the ranking of the same countries with respect to their relative importance in the trade of the given country. The results obtained, for several given countries, are given in Table 6. between distance and trade, and (2) this correlation appears to be about equal for imports and exports.

In order to evaluate the significance of these coefficients, however, an important point must be now introduced. Since one country's imports are another country's exports the actual distribution of (say) the first country's imports will depend on a mixture of two distance elements: (I) the relative distance of every other country to the given country, which will influ-

Tabie 6. - Rank Correlation Coefficients, Distance and Trade *

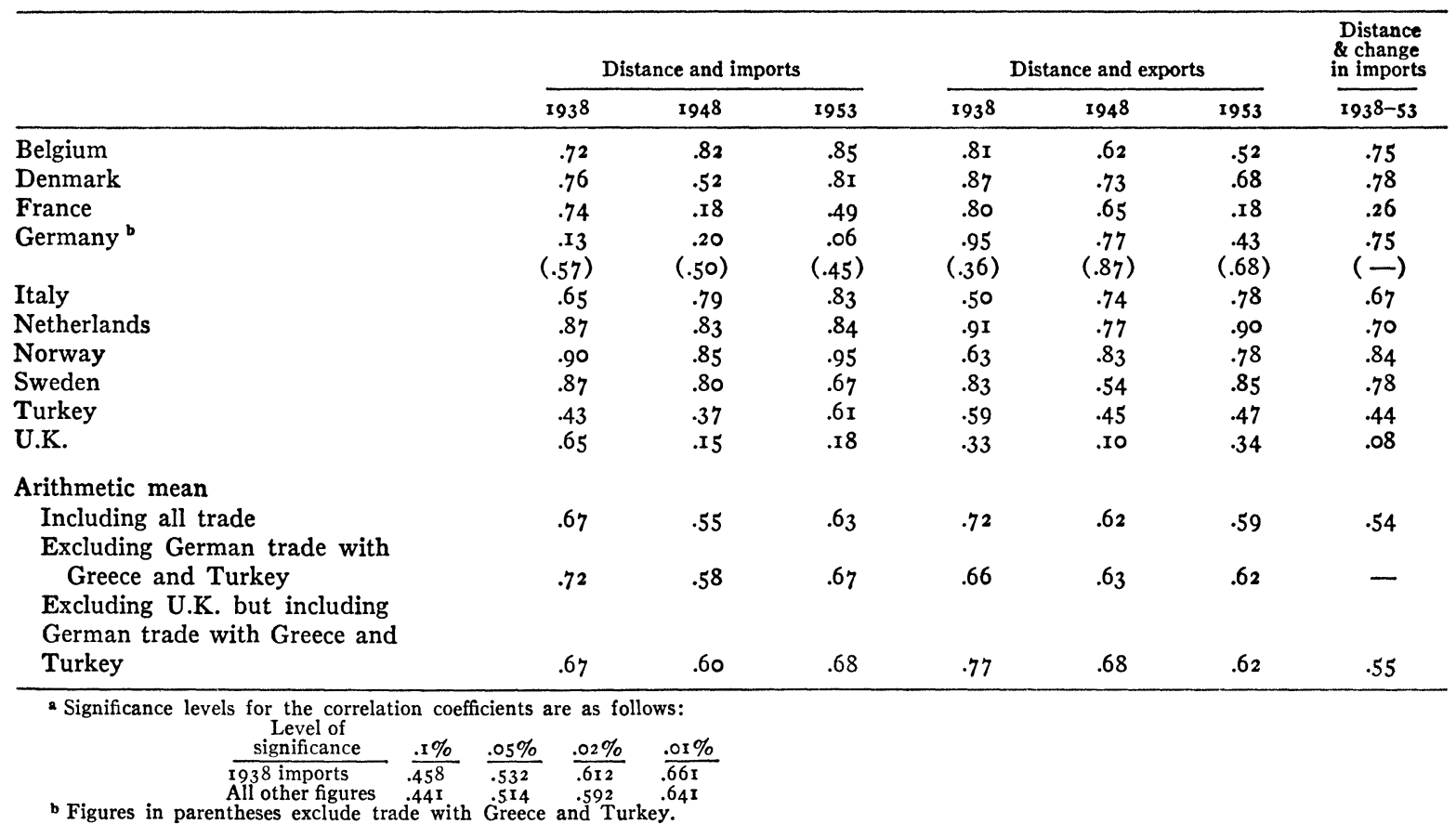

It should be noted that the right-hand column of Table 6 constitutes a check on the possibility of having made errors in the ranking of distance which fortuitously increase the correlation coefficients. For the same distance ranking is, of course, used for the calculations relating to the pattern of trade in the given years and for the changes in the pattern over time. A distance ranking which was fortuitous from the point of view of the former would not necessarily be so from the point of view of the latter.

The last three rows in this table seem to confirm two of the conclusions reached above, namely, (I) there is a fairly strong correlation ence the import pattern of the given country in one way; and (2) the relative distance of the given country to each other country, which will affect the export pattern of each other country and will thereby also have an effect on the import pattern of the given country.

Relative distances in the economic sense are not symmetrical - the United Kingdom may be the nearest country to Ireland, but Ireland is not necessarily the nearest country to the United Kingdom. Thus although the United Kingdom may be highly placed in Irish imports on account of her proximity to Ireland, another tendency may be at work sending United Kingdom exports to countries such as 
France, which are "nearer" the United Kingdom than Ireland is. ${ }^{8}$

To sum up: since (I) relative distances will affect both the distribution of exports and imports, (2) each country's exports are some other country's imports, and vice versa, and (3) relative distances are not necessarily symmetrical, the final pattern of trade will be a mixture of the various pulls, the export pull against the import pull. This means that it would be most unlikely to obtain for all countries high rank correlation coefficients for both imports and exports. For if, for example, import patterns of all countries were found to have correlation coefficients of nearly unity when compared with ranked relative distances, this would suggest that the influence of distance on export patterns would be small unless there were a high degree of symmetry in relative distances. That a considerable degree of symmetry must exist can be seen from the fact that in Table 6 both the import and the export coefficients are, on the whole, fairly high.

This does not mean, of course, that other determinants such as changes in relative incomes and prices have not had any influence on trade patterns. For the correction factor used on the data (to an equal importer or equal exporter basis) has eliminated such determinants as regards their influence on the pattern of each country's trade in the given years and hence as regards their influence on changes in the pattern. To compare the influence of distance with that of the other determinants would be a much more difficult problem, for while the technique used above can show the influence of distance other things being equal, ${ }^{9}$ it is not possible to calculate the influence of other things (such as prices and incomes), distances being equal, until a tech-

\footnotetext{
${ }^{8}$ In a more formal manner one can envisage a trade matrix transformed into a matrix in which coefficients allocate each country's imports on the basis of the relative distance of each other country. Similarly the transformation could be made to one in which coefficients apply to each country's exports. The relative strength of the resulting two coefficients applying to each box in the matrix will determine the final value of the relevant element of the matrix.

${ }^{9}$ Roughly speaking, the correction to equal exporter basis wipes out differences in competitiveness, among other things; and the correction to equal importer basis wipes out differences in relative incomes, among other things.
}

nique is found for adjusting data to an "equal distance" basis. For this, mere ranking is of course insufficient.

Conclusions. Apart from the specific conclusions already mentioned above, the basic tables show a tendency on the part of the lessdeveloped countries of Europe to concentrate their trade more than the other countries. The concentration is also very closely linked to neighboring countries. Now it is not surprising that this should be the case, since the less-developed countries will, in general, have less diversified economies; this will in practice (though with no absolute theoretical necessity), lead to relative concentration countrywise of total trade. What is interesting is the possibility of a causal connection between degree of development and distance. This requires the notion of "absolute distance," not merely of relative distance, to and from other countries - of being, in an absolute sense, far away or near to other countries as a whole. The fact that the countries on the periphery of Europe tend to have less-developed economies (Iceland, Portugal, southern Italy, Greece, and Turkey) may be due partly to their being simply "far away" from everybody that matters in trade. ${ }^{10}$ The Scandinavian group of countries may constitute the exception that proves the rule. For the countries nearest to them are Germany and the United Kingdom, two very important traders and two countries with which they are connected by sea-passage - the cheapest form of transport. The fact that the great distance of Turkey and Greece from the major trading countries of Europe is offset by their proximity to Russia and Eastern Europe has been poor compensation, for these countries have been far less important traders than the countries of northwest Europe.

This view can, of course, be developed along many lines. The main implication in the field of the economics of underdeveloped areas, for example, is to confirm the fact that means of transport usually constitute the most useful form of overhead capital. What is important, in other words, is to be "near" other countries

\footnotetext{
${ }^{10}$ It has been pointed out above that relative distances are not necessarily symmetrical. Thus it is possible for a country not to be relatively near any other country. Such a country is "far away" in an absolute sense.
} 
- preferably important countries. The rapid development of the Canadian economy is no doubt largely due to proximity to the United States. It is probable that the favorable prospects for Latin America are also related to the same cause.

As well as speculating on the future relative rates of growth in terms of nearness, it would be interesting to speculate on the effects of changes in modes of transport and transport costs. Apart from the general reduction in economic distances which would result from a reduction in the costs of air freight, for example, a special problem is posed by the existence of "psychic" distance. It is probable that the manner in which the purchases of raw materials by a firm are distributed geographically will depend partly on the extent to which foreign sources have been personally contacted and cultivated. While the transport costs paid (directly or indirectly) by an Italian entrepreneur on a raw material supplied by Turkey may be no greater (as the material may come by sea) than the same material supplied by Switzerland, he is more likely to have contacts with Swiss suppliers, since Switzerland will be "nearer" to him in a psychic evaluation (fewer language difficulties, and so on), as well as in the economic sense that air travel will absorb less of his time. The growth of air travel and freighting would not only tend to iron out discrepancies arising from sea versus rail transport (as the aircraft travel, in general, along straight lines - or great circles) but would have very interesting repercussions on psychic distances. 

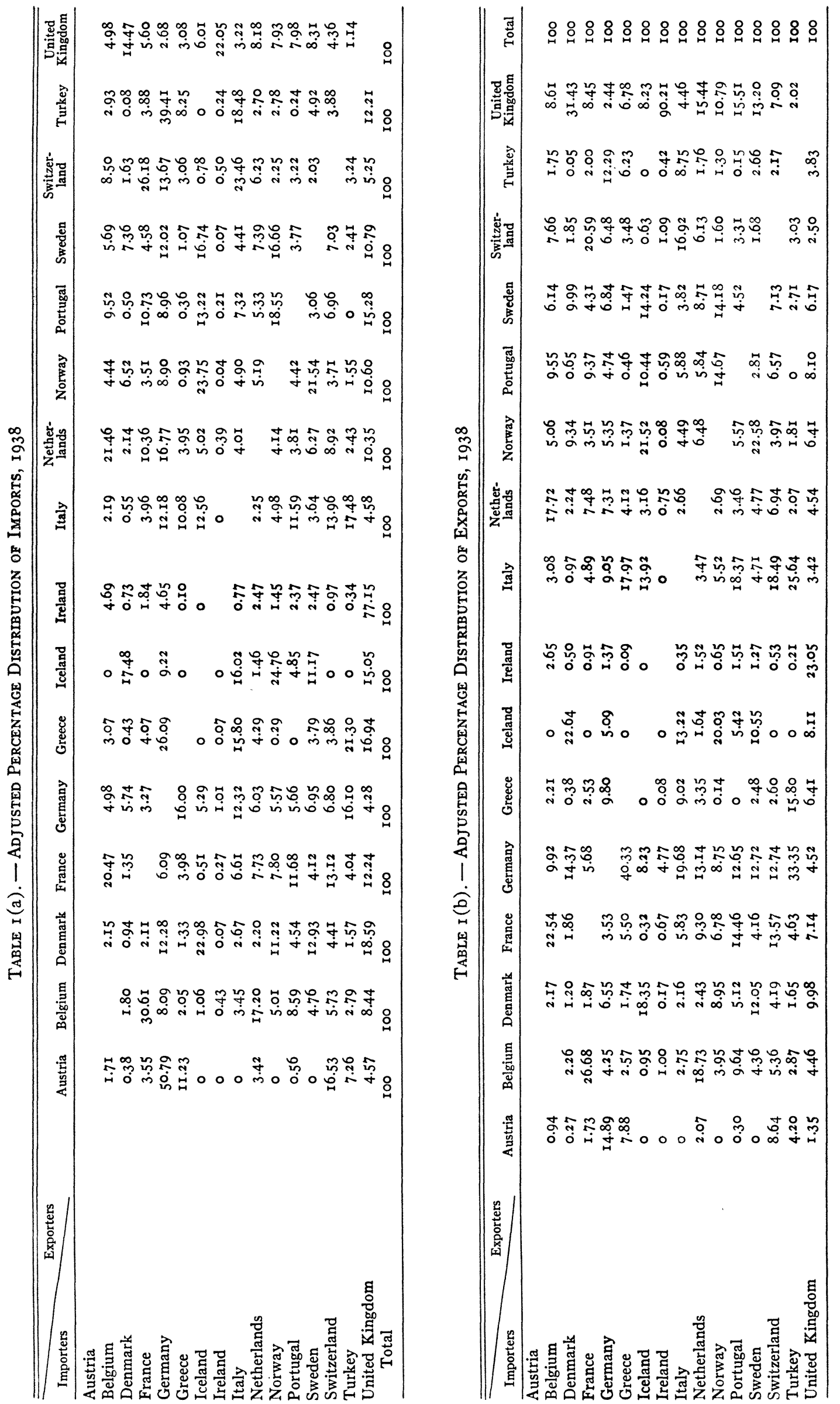

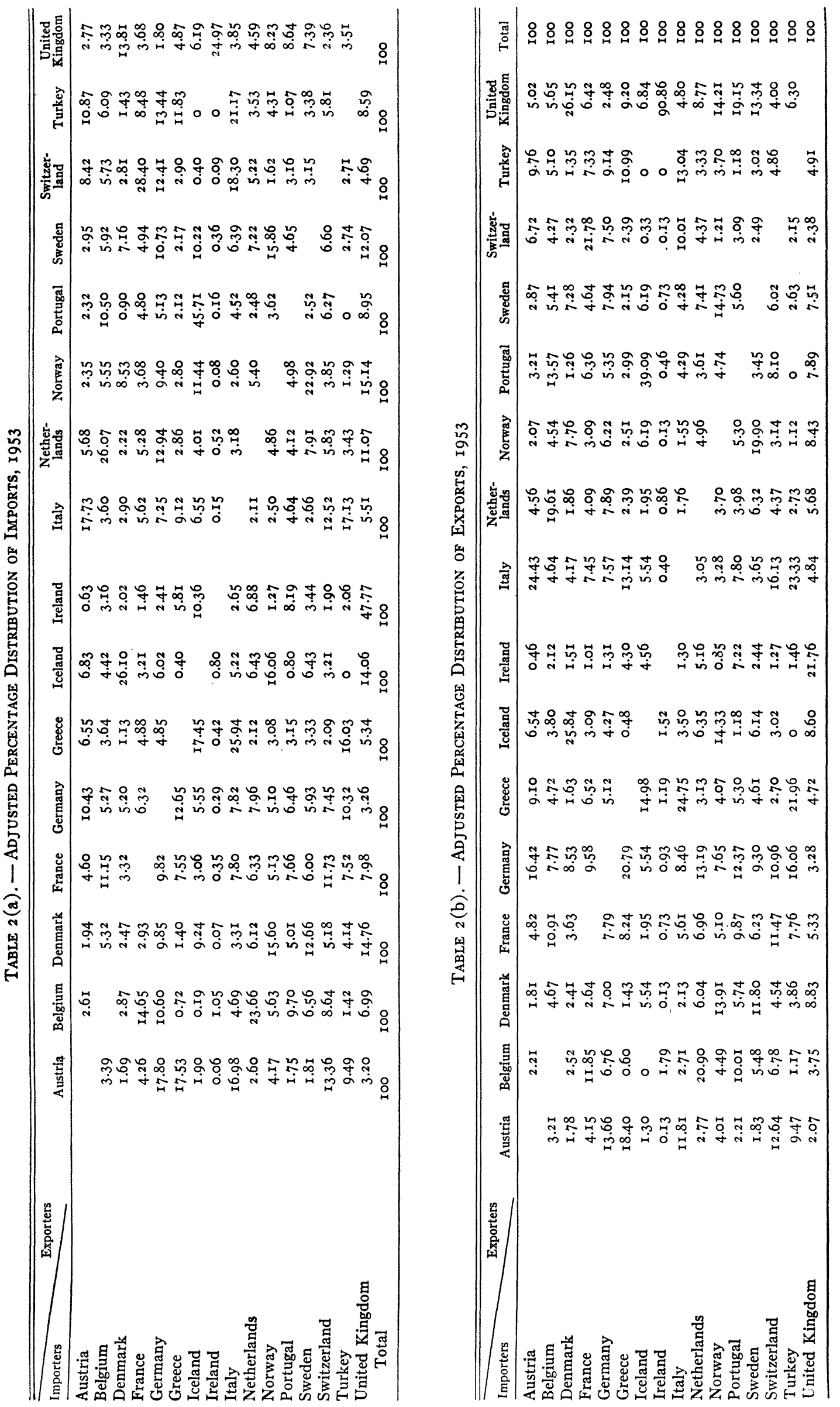